\title{
Tricuspid annular dimensions in patients with severe mitral regurgitation without severe tricuspid regurgitation
}

\author{
Sohum Kapadia ${ }^{1}$, Amar Krishnaswamy ${ }^{1}$, Habib Layoun ${ }^{1}$, Brian P. Griffin ${ }^{1}$, Per Wierup ${ }^{2}$, \\ Paul Schoenhagen ${ }^{3}$, Serge C. Harb ${ }^{1}$ \\ ${ }^{1}$ Department of Cardiovascular Medicine, Heart, Vascular, and Thoracic Institute, Cleveland Clinic, Cleveland, OH, USA; ${ }^{2}$ Department of \\ Cardiovascular Surgery, Heart, Vascular, and Thoracic Institute, Cleveland Clinic, OH, USA; ${ }^{3}$ Department of Diagnostic Radiology, Heart, Vascular, \\ and Thoracic Institute, Cleveland Clinic, Cleveland, OH, USA \\ Contributions: (I) Conception and design: S Kapadia, SC Harb; (II) Administrative support: SC Harb; (III) Provision of study materials or patients: \\ S Kapadia, SC Harb; (IV) Collection and assembly of data: S Kapadia, SC Harb; (V) Data analysis and interpretation: S Kapadia, SC Harb; (VI) \\ Manuscript writing: All authors; (VII) Final approval of manuscript: All authors. \\ Correspondence to: Serge C. Harb, MD, FACC. 9500 Euclid Avenue, J1-126, Cleveland, OH 44195, USA. Email: harbs@ccf.org.
}

Background: Concomitant TV repair during mitral valve (MV) surgery based on tricuspid valve annulus (TVA) dilation, rather than the degree of tricuspid regurgitation (TR), is beneficial and supported by the valve guidelines. We sought to determine TVA geometry and dimensions in controls and assess the changes that occur in patients with severe primary (PMR) and secondary (SMR) mitral regurgitation without TR.

Methods: We analyzed cardiac computed tomographic angiography (CCTA) of 125 consecutive subjects: 50 controls with normal coronary CCTA and no valvular dysfunction, 50 PMR patients referred for robotic repair, and 25 SMR patients referred for transcatheter therapy. Patients with $>2+$ TR on echocardiography were excluded. Annular measurements were performed using dedicated software and compared. Correlations and determinants of TVA dimensions were analyzed.

Results: Patients with SMR were older and had significantly more comorbidities. In controls, the TVA was larger and more planar and eccentric compared to the $M V$ annulus (all $\mathrm{P}<0.01$ ). Dimensions of both annuli correlated significantly ( $r \geq 0.5 ; \mathrm{P}<0.001$ for all dimensions) in controls and patients with severe MR. In both PMR and SMR, the TVA enlarged in all dimensions $(\mathrm{P}<0.01)$ with a trend towards becoming more circular. On multivariable regression, the MV annular area was the primary determinant of the TVA area (adjusted $\beta=0.430, \mathrm{P}<0.001)$.

Conclusions: Substantial changes in TVA dimensions are encountered in patients with severe MR even in the absence of severe TR such that TVA and MVA dimensions remain correlated. Close attention to the TVA in patients with severe MR is warranted.

Keywords: Tricuspid annulus; mitral annulus; severe mitral regurgitation

Submitted Nov 03, 2020. Accepted for publication Dec 28, 2020.

doi: $10.21037 / \mathrm{cdt}-20-903$

View this article at: http://dx.doi.org/10.21037/cdt-20-903

\section{Introduction}

Since the early report from Levine and colleagues (1) describing the complex non-planar saddle contour of the mitral valve annulus (MVA), many studies, both based on echocardiography (2-4) and cardiac computed tomographic angiography (CCTA) (5-8), have investigated its shape and geometry and the pathologic changes that can occur in different types of valvular disease. Similarly, but to a lesser extent, there have been separate studies examining the tricuspid valve annulus (TVA), an equally complex threedimensional structure (9-11), and the changes that occur in 
secondary tricuspid regurgitation (TR) (12-14) which is the most common form of disease affecting the tricuspid valve (TV) (15).

However, only a few small studies (and none based on CCTA) have concomitantly examined both annuli (16-18), and these were almost exclusively in normal healthy subjects. The importance of assessing the TVA changes that occur in MV disease was highlighted by Dreyfus and colleagues $(19,20)$, who advocated TV repair based on the degree of TVA dilation irrespective of the grade of TR. Annular dilation has been extensively and consistently shown to be a major determinant for the development of significant TR (21-23). Early identification of annular changes and potential interventions may improve right ventricular remodeling and halt the progression to severe TR, thus improving outcomes $(19,24)$. Based on these findings, the valve guidelines support TV repair in patients undergoing left-sided surgery, based on TVA dilation alone (15).

We sought to concomitantly examine the MVA and TVA geometry and dimensions in control subjects without mitral or tricuspid valve dysfunction and patients with severe primary (PMR) or secondary (SMR) mitral regurgitation but without severe TR using CCTA.

We present the following article in accordance with the STROBE reporting checklist (available at: http://dx.doi. org/10.21037/cdt-20-903).

\section{Methods}

The study was conducted in accordance with the Declaration of Helsinki (as revised in 2013). The study was approved by the Institutional Review Board of the Cleveland Clinic Foundation (No. 19-811) with a waiver for informed consent.

\section{Study population}

Three cohorts were identified by consecutive review of gated CCTA scans performed at our institution starting in January 2018, according to the scan indication (Figure 1). For the control cohort, we studied 50 consecutive subjects who underwent a coronary CCTA for atypical chest discomfort. We only included those with normal coronary anatomy, no abnormal cardiac findings, and no known other cardiac comorbidities. Thirty-eight $(76 \%)$ of these patients also had echocardiograms available showing normal biventricular size and function, normal biatrial size, and no significant MR or TR. For PMR, we included the first 50 patients referred for cardiac computed tomography (CT) as part of planning for robotic mitral valve (MV) repair. All patients had echocardiograms available with findings of myxomatous MV disease, severe mitral regurgitation, and normal left ventricular function. We excluded patients with associated significant $(\geq 3+)$ TR $(\mathrm{N}=1)$. Only 1 PMR patient had 2+ TR. For SMR, we included the first 25 patients referred for cardiac CT as part of planning transcatheter MV intervention (TMVI), specifically for SMR, as determined by the multidisciplinary valve team. All patients had echocardiograms available showing left ventricular dysfunction, severe $M R$, and the mechanism of MR described as functional/secondary. We also excluded those with associated significant $(\geq 3+)$ TR $(\mathrm{N}=1) ; 7$ SMR patients had 2+ TR.

\section{Cardiac CT data acquisition}

All CCTA were contrast-enhanced (Omnipaque 350, GE Healthcare) and ECG synchronized, performed with multi-detector CT technology (Siemens Definition Flash or Somatom Force dual-source). Imaging was acquired during a single breath-hold. The tube voltage and current were determined according to the patient's size. Scan range extended from the carina to just below the heart for controls and SMR patients and to the pelvis for PMR patients.

For the control group, coronary CT scans were typically acquired with prospective triggering in diastole $(65-70 \%$ interval). In the case of retrospective acquisition $(\mathrm{N}=5)$, diastolic acquisition at the $70 \%$ phase was selected for analysis. All SMR patients underwent a retrospectively gated-acquisition with reconstructions at $10 \%$ intervals of the cardiac cycle, where the $70 \%$ phase was chosen for analysis. For PMR patients, the protocol consisted of a prospectively triggered helical high-pitch acquisition in mid diastole ( 70\% phase).

\section{CT data analysis}

All CT measurements were performed offline using dedicated software for annular segmentation (Aquarius iNtuition v4.4.13, TeraRecon, Foster City, California). Two authors (SK and SCH) performed all MVA and TVA annular measurements by co-review. The method for segmentation of the annulus was performed as previously described for the MVA after identifying the trigones $(6,25)$, but with the inclusion of the anterior MVA horn (Figure 2) to represent the 3D saddle shape of the annulus fully. A 


\begin{tabular}{|c|c|c|}
\hline Consecutive coronary CTAs & $\begin{array}{l}\mathrm{N}=56 \text { excluded } \\
\text { - Coronary artery disease: } 17 \\
\text { - Coronary artery anomaly (origin, aneurysm, dissection, } \\
\text { myocardial bridge): } 18 \\
\text { - Aortic or mitral valve disease: } 8 \\
\text { - Aortic aneurysm: } 6 \\
\text { - Others (HOCM, Pectus, prior surgery): } 6 \\
\text { - Atrial fibrillation: } 1\end{array}$ & 50 controls \\
\hline $\begin{array}{l}\text { Consecutive "robotic" mitral } \\
\text { valve repair CTAs }\end{array}$ & $\begin{array}{l}1 \text { excluded for significant }(3+) \\
\text { tricuspid regurgitation }\end{array}$ & 50 PMR \\
\hline $\begin{array}{l}\text { Consecutive CTAs for TMVI for } \\
\text { Secondary MR }\end{array}$ & $\begin{array}{l}1 \text { excluded for significant (3+) } \\
\text { tricuspid regurgitation }\end{array}$ & 25 SMR \\
\hline
\end{tabular}

Figure 1 Flow diagram of the study participants. Consecutive CCTA were reviewed for inclusion; 56 controls were excluded for the reasons detailed above. One patient in each PMR and SMR groups were excluded for the presence of significant $>2+$ tricuspid regurgitation. CTA, computed tomographic angiography; CCTA, cardiac computed tomographic angiography; HOCM, hypertrophic obstructive cardiomyopathy; TMVI, trancatheter mitral valve intervention; MR, mitral regurgitation; PMR, primary mitral regurgitation; SMR, secondary mitral regurgitation.
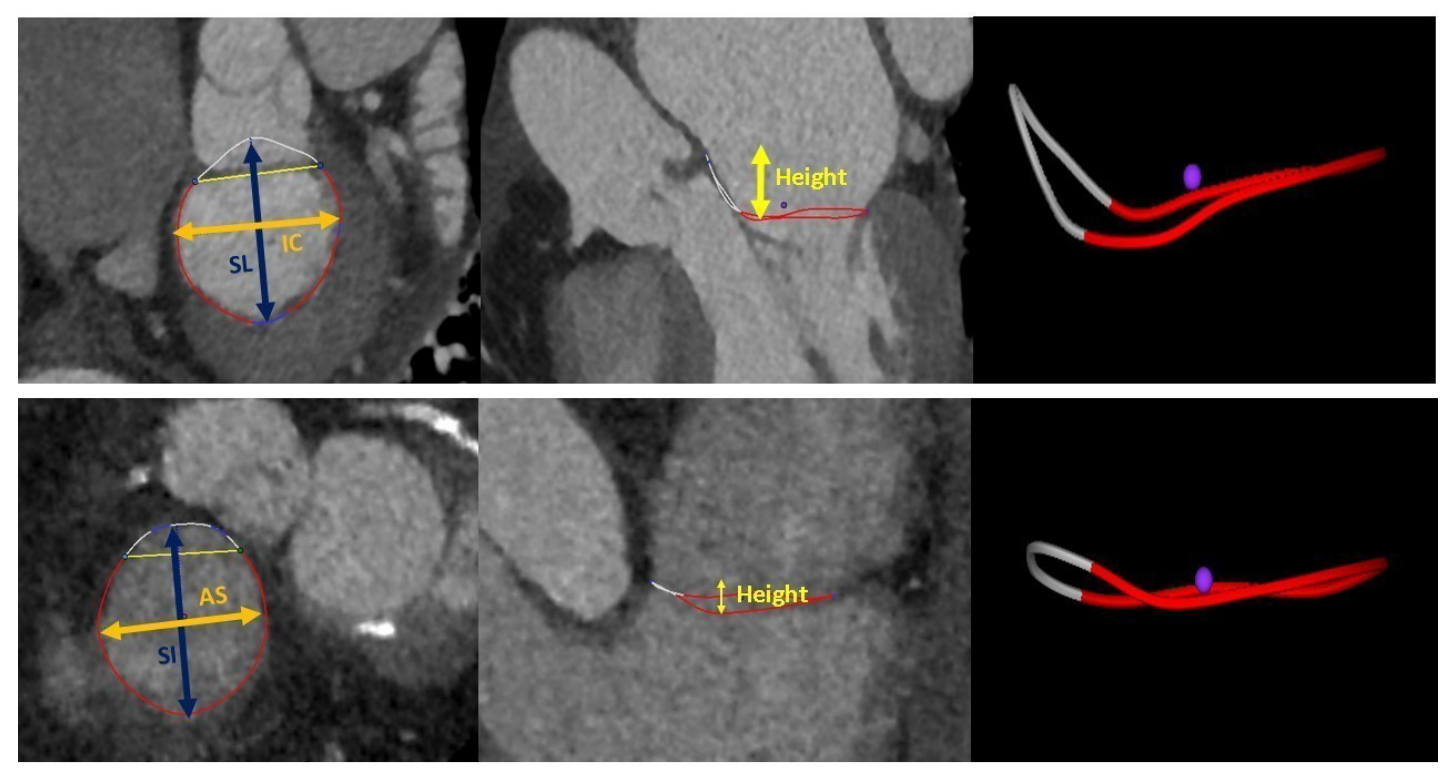

Figure 2 Mitral valve annular (upper panels) and tricuspid valve annular (lower panels) segmentation and dimensions. Both annuli were segmented using dedicated software. Projected annular area and perimeter, and annular distances and height were measured, as depicted. The images to the right show the 3D spatial annular representation. IC, intercommissural distance; SL, septo-lateral distance; AS, anteroseptal distance; SI, supero-inferior distance.

similar method was used to segment the TVA. Briefly, the MVA and TVA axes passing through the center of the valves were first identified. Then, 12 planes, evenly rotated (every 30 degrees) around these axes, were automatically defined.

The annular contour was generated by cubic-spline interpolation of seeding points manually placed along the annular insertion. The saddle-shaped configuration of the annulus was adopted. All measurements were obtained by the least-squares plane method projection fitted to the annulus contour. In addition to the annulus 
area and projected perimeter, the septo-lateral (SL) and intercommissural (IC) distances of the MVA were measured in accordance with prior reports $(6,25)$. For the TVA, we measured the superoinferior (SI) distance as the maximal length extending along the superior-inferior axis (superior and inferior vena cava) parallel to the chest wall, and the anteroseptal (AS) distance as the maximal distance orthogonal to the SI distance/chest wall (Figure 2). While prior TVA studies $(13,22)$ have referred to the SI dimension as anteroposterior and AS as septolateral, we adopted SI and AS as better anatomic descriptors of the measurements for our study. The height of the annulus was measured as the orthogonal distance between the highest and lowest points along the z-axis. The eccentricity index was calculated as IC/SL for the MVA and SI/AS for the TVA. The atrial areas were measured as a projected area on a reconstructed 4-chamber view.

\section{Echocardiographic data}

All echocardiograms were performed within one year of the CCTA, except for controls where the echocardiograms were more than a year apart in 16 subjects. The reports were reviewed, and the following variables extracted: degree of MR (1+ to 4+), effective regurgitant orifice area (EROA) as measured by the proximal isovolumetric surface area (PISA) method, degree of TR (1+ to 4+), estimated right ventricular systolic pressure (RVSP) in $\mathrm{mmHg}$, left ventricular ( $\mathrm{LV}$ ) end-diastolic volume (in $\mathrm{mL}$ ), and $\mathrm{LV}$ ejection fraction (\%). The right ventricular (RV) size and function were qualitatively assessed, and we dichotomized them as normal in size $v s$. dilated and normal in function $v s$. dysfunctional.

\section{Statistical analysis}

Normality was assessed with the Shapiro-Wilk statistic. Categorical variables are presented as number (percentage) and continuous variables as mean $\pm \mathrm{SD}$ or median $\left(25^{\text {th }}, 75^{\text {th }}\right.$ percentile). All measurements were also indexed to body surface area (BSA), as prior studies have shown that these dimensions vary with BSA $(3,6,11)$. Categorical variables were compared using the Chi-square test. For continuous variables, when comparing between two groups, we used the Student $t$-test (normal distribution) or the MannWhitney $U$ test (for non-normally distributed data). When comparing three groups, we used the ANOVA method with post hoc analysis using the Tukey's test. For correlations, we used the Spearman test. To assess the predictors of the TVA area adjusted to BSA, we performed multivariable linear regression. Only variables that were significantly correlated with the dependent variable were included. We also excluded independent covariates that were significantly inter-correlated $(\mathrm{R} \geq 0.6)$ to avoid collinearity. Statistical analyses were performed using SPSS Statistics 24 (IBM Corp., Armonk, New York, USA). A 2-tailed P value $<0.05$ was considered statistically significant.

\section{Results}

\section{Patient characteristics}

The baseline clinical, echocardiographic, and CCTA characteristics are presented in Table 1. The SMR group had significantly more comorbid conditions compared to PMR and controls, including coronary artery disease and atrial fibrillation (both $\mathrm{P}<0.001$ ). The SMR group also displayed significant differences in the echocardiographic findings (all $\mathrm{P}<0.001)$ with lower ejection fraction, more frequent $\mathrm{RV}$ dilation and dysfunction, and higher estimated RVSP.

\section{Comparison between the MVA and TVA dimensions in controls}

In the control group, the indexed TVA area, perimeter, and SI and AS distances were significantly larger (all $\mathrm{P}$ values $<0.01$ ) than the MVA area, perimeter, and IC and SL distances, respectively (Table 2).

While the eccentricity index of the TVA was significantly larger compared to that of the MVA ( $\mathrm{P}=0.004)$, the annular height was significantly higher for the MVA $(\mathrm{P}<0.001)$.

A strong $(r \geq 0.5)$ and significant $(\mathrm{P}<0.001)$ correlation was found between the indexed MVA and TVA areas $(\mathrm{r}=0.585)$, perimeters $(\mathrm{r}=0.877)$, IC and SI distances $(\mathrm{r}=0.831)$, and SL and AS distances ( $\mathrm{r}=0.670)$, respectively, in the control group (Figure 3).

\section{MVA dimensions in PMR and SMR patients}

When comparing the MVA dimensions across the three groups of patients, MVA dimensions (area, perimeter, and IC and SL distances) were significantly increased in both PMR and SMR groups compared to controls $(\mathrm{P}<0.001)$. On post hoc analysis, the PMR group tended to have larger dimensions compared to SMR, with the non-indexed and indexed MVA (Tukey's test $\mathrm{P}=0.001$ and 0.013 , respectively), 
Table 1 Baseline clinical, echocardiographic, and CCTA characteristics

\begin{tabular}{|c|c|c|c|c|}
\hline Variable & Controls $(\mathrm{N}=50)$ & $\operatorname{SMR}(\mathrm{N}=25)$ & $\operatorname{PMR}(\mathrm{N}=50)$ & $P$ value \\
\hline Age (years) & $48[38,55]$ & $70[63,77.5]$ & $55[48,59]$ & $<0.001$ \\
\hline Female (\%) & 48 & 52 & 38 & 0.435 \\
\hline BMI $\left(k g / m^{2}\right)$ & $29.51[24.18,34.75]$ & $26.06[23.33,27.69]$ & $25.71[22.96,27.82]$ & 0.002 \\
\hline Diabetes (\%) & 2 & 28 & 0 & $<0.001$ \\
\hline Hypertension (\%) & 24 & 76 & 30 & $<0.001$ \\
\hline Hyperlipidemia (\%) & 12 & 44 & 30 & 0.007 \\
\hline Current Smoking (\%) & 8 & 20 & 2 & 0.026 \\
\hline \multicolumn{5}{|l|}{ Echocardiographic and CCTA data } \\
\hline Radiation dose (DLP in mGycm) & $386[259,577.5]$ & $914[659.5,1,244.5]^{\star *}$ & $408.5[283.5,508.75]$ & $<0.001$ \\
\hline EROA $\left(\mathrm{cm}^{2}\right)$ & N/A & $0.32[0.29,0.41]$ & $0.63[0.47,0.96]$ & $<0.001^{*}$ \\
\hline LVEF (\%) & $61.5[60,66]$ & $32[23,40]$ & $66[60,69.25]$ & $<0.001$ \\
\hline LVEDV/BSA $\left(\mathrm{ml} / \mathrm{m}^{2}\right)$ & $46.12[40.86,53.75]$ & $95.69[73.05,135.4]$ & $74.95[59.47,91.06]$ & $<0.001$ \\
\hline $\mathrm{LA}$ area $\left(\mathrm{cm}^{2} / \mathrm{m}^{2}\right)$ & $8.25[6.95,9.15]$ & $16.82[13.17,18.06]$ & $12.97[10.69,15.75]$ & $<0.001$ \\
\hline RV dilation (\%) & 0 & 36 & 4 & $<0.001$ \\
\hline RV dysfunction (\%) & 0 & 48 & 2 & $<0.001$ \\
\hline
\end{tabular}

Data are presented as mean \pm SD or median [25th, 75th percentile] for continuous measures and \% for categorical measures. *, only PMR and SMR groups were compared. The control group was not included. ${ }^{*}$, SMR patients had a retrospective multiphase acquisition throughout the cardiac cycle without dose modulation. In contrast, PMR patients had a single phase prospective acquisition. BMI, body mass index; BSA, body surface area; DLP, dose-length product; EROA, effective regurgitant orifice area; N/A, not assessable; LVEF, left ventricular ejection fraction; LVEDV, left ventricular end-diastolic volume; LA, left atrium; RV, right ventricle; RA, right atrium; RVSP, right ventricular systolic pressure; PMR, primary mitral regurgitation; SMR, secondary mitral regurgitation.

non-indexed perimeter (Tukey's test $\mathrm{P}=0.001$,) non-indexed SL and IC distances (Tukey's test $\mathrm{P}=0.033$ and 0.001 , respectively) significantly larger in PMR compared to SMR. However, the indexed perimeter (Tukey's test $\mathrm{P}=0.333$ ) and indexed SL and IC distances (Tukey's test $\mathrm{P}=0.899$ and 0.217 , respectively) were not significantly different (Table 3).

There were no differences in terms of annular height between the three groups (non-indexed $\mathrm{P}$ value $=0.835$ and indexed $\mathrm{P}$ value $=0.118$ ). However, when comparing the annular eccentricity, the MVA became more circular in SMR and PMR $(\mathrm{P}=0.002)$, with a significant decrease in the eccentricity index in both MR groups compared to controls (Tukey's test $\mathrm{P}=0.003$ and $\mathrm{P}=0.016$; respectively).

\section{TVA dimensions in PMR and SMR patients}

Both PMR and SMR patients had significant changes in the TVA dimensions compared to controls. These changes were consistent in terms of larger non-indexed and indexed areas and perimeters, and indexed distances. On post hoc analysis, the SMR group had even larger dimensions compared to PMR in non-indexed and indexed areas (Tukey's test 
Table 2 Comparison of mitral $v s$. tricuspid dimensions in controls

\begin{tabular}{|c|c|c|c|}
\hline Variable & Mitral valve & Tricuspid valve & $P$ value \\
\hline Annular area $\left(\mathrm{cm}^{2}\right)$ & $10.40 \pm 1.71$ & $12.64 \pm 2.25$ & $<0.001$ \\
\hline Area/BSA $\left(\mathrm{cm}^{2} / \mathrm{m}^{2}\right)$ & $5.1 \pm 0.86$ & $6.27 \pm 1.47$ & $<0.001$ \\
\hline Projected perimeter $(\mathrm{mm})$ & $116.16 \pm 9.93$ & $130.9 \pm 11.32$ & $<0.001$ \\
\hline Perimeter/BSA (mm) & $57.38 \pm 8.18$ & $64.99 \pm 11.54$ & $<0.001$ \\
\hline $\mathrm{IC} / \mathrm{BSA}$ and $\mathrm{SI} / \mathrm{BSA}\left(\mathrm{mm} / \mathrm{m}^{2}\right)$ & $19.28 \pm 2.65$ & $22.38 \pm 4.46$ & $<0.001$ \\
\hline SL and AS distances $(\mathrm{mm})$ & $33.68 \pm 3.23$ & $36.16 \pm 5.50$ & 0.003 \\
\hline SL/BSA and AS/BSA distances $\left(\mathrm{mm} / \mathrm{m}^{2}\right)$ & $16.64 \pm 2.61$ & $17.94 \pm 3.71$ & 0.002 \\
\hline IC/SL and SI/AS ratios & $1.16 \pm 0.11$ & $1.27 \pm 0.24$ & 0.004 \\
\hline
\end{tabular}

IC, intercommissural distance; SL, septo-lateral distance; AS, antero-septal distance; SI, supero-inferior distance; BSA, body surface area.
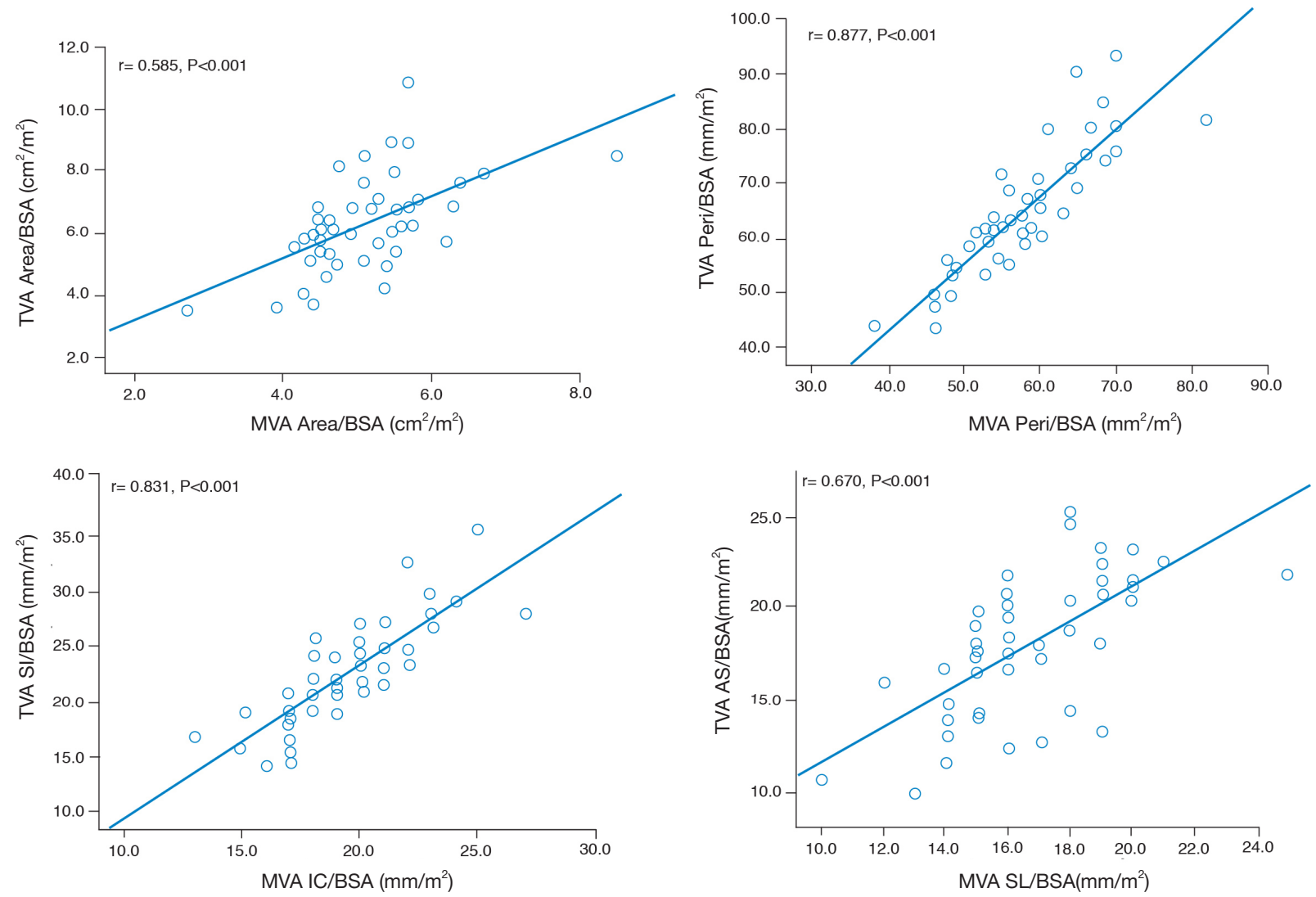

Figure 3 Correlations between mitral and tricuspid valves annular dimensions in controls. Correlations between MVA and TVA areas and perimeters, IC and SI distances, and SL and AS distances in controls. All dimensions are indexed to BSA (body surface area). MVA, mitral valve annulus; TVA, tricuspid valve annulus; Peri, perimeter; IC, intercommissural distance; SL, septo-lateral distance; AS, antero-septal distance; SI, supero-inferior distance. 
Table 3 Mitral valve annular dimensions in controls, primary, and secondary mitral regurgitation

\begin{tabular}{|c|c|c|c|c|c|c|}
\hline Variable & $\begin{array}{l}\text { Controls } \\
(\mathrm{N}=50)\end{array}$ & SMR (N=25) & PMR (N=50) & $\begin{array}{l}\text { ANOVA P } \\
\text { value }\end{array}$ & $\begin{array}{l}\text { Post hoc Tukey's test } \\
\text { interpretation }\end{array}$ & $\begin{array}{l}\text { Tukey's test P values: SMR } \\
\text { vs. controls; PMR vs. controls; } \\
\text { PMR vs. SMR; respectively }\end{array}$ \\
\hline MVA area/BSA $\left(\mathrm{cm}^{2} / \mathrm{m}^{2}\right)$ & $5.1 \pm 0.86$ & $7.54 \pm 1.69$ & $8.55 \pm 1.73$ & $<0.001$ & PMR $>$ SMR > controls & $<0.001 ;<0.001 ; 0.013$ \\
\hline MVA perimeter (mm) & $116.16 \pm 9.93$ & $133.48 \pm 15.21$ & $146.18 \pm 16.38$ & $<0.001$ & PMR $>$ SMR $>$ controls & $<0.001 ;<0.001 ; 0.001$ \\
\hline MVA SL distance (mm) & $33.68 \pm 3.23$ & $40.12 \pm 5.07$ & $43.16 \pm 6.05$ & $<0.001$ & PMR $>$ SMR > controls & $<0.001 ;<0.001 ; 0.033$ \\
\hline $\begin{array}{l}\text { MVA SL distance/BSA } \\
\left(\mathrm{mm} / \mathrm{m}^{2}\right)\end{array}$ & $16.64 \pm 2.61$ & $22.20 \pm 3.29$ & $22.52 \pm 3.13$ & $<0.001$ & PMR $=$ SMR $>$ controls & $<0.001 ;<0.001 ; 0.899$ \\
\hline MVA IC distance (mm) & $39.20 \pm 3.98$ & $43.24 \pm 5.07$ & $47.46 \pm 5.25$ & $<0.001$ & PMR $>$ SMR $>$ controls & $0.002 ;<0.001 ; 0.001$ \\
\hline $\begin{array}{l}\text { MVA height/BSA } \\
\left(\mathrm{mm} / \mathrm{m}^{2}\right)\end{array}$ & $5.78 \pm 2.02$ & $6.68 \pm 1.73$ & $6.14 \pm 1.47$ & 0.118 & $\mathrm{PMR}=\mathrm{SMR}=$ controls & $\mathrm{N} / \mathrm{A}$ \\
\hline MVA ratio: IC/SL & $1.16 \pm 0.11$ & $1.08 \pm 0.09$ & $1.11 \pm 0.11$ & 0.002 & $\mathrm{PMR}=\mathrm{SMR}<$ controls & $0.003 ; 0.016 ; 0.560$ \\
\hline
\end{tabular}

MVA, mitral valve annulus; IC, intercommissural distance; SL, septo-lateral distance; BSA, body surface area; PMR, primary mitral regurgitation; SMR, secondary mitral regurgitation.

$\mathrm{P}=0.005$ and $<0.001$, respectively), perimeters (Tukey's test $\mathrm{P}=0.014$ and 0.003 , respectively), and indexed SI (Tukey's test $\mathrm{P}=0.02$ ) and AS distances (Tukey's test $\mathrm{P}=0.004$ ) (Table 4).

The TVA height did not change among the three groups (ANOVA P value $=0.766$ ). When comparing the eccentricity index, there was a statistically significant difference among the three groups $(\mathrm{P}$ value $=0.029)$, with a trend towards a decrease in both SMR ( $\mathrm{P}$ value $=0.062)$ and $\mathrm{PMR}$ ( $\mathrm{P}$ value $=0.068)$ groups compared to controls.

\section{Correlations between the MVA and TVA dimensions in PMR and SMR}

In both PMR and SMR groups, MVA and TVA area, perimeters, IC and SI distances, and SL and AS distances remained largely $(r \geq 0.5)$ and significantly $(P<0.01)$ correlated, with more pronounced TVA changes for similar MVA dimensions in SMR compared to PMR (Figure 4).

\section{Predictors of indexed TVA area}

The univariable correlates of the indexed TVA area are listed in Table 5. Age, but not gender, was significantly correlated. The indexed MVA area and indexed RA area showed strong correlations. The LVEF, indexed LVEDV, RVSP, and presence of dysfunctional RV showed moderate correlation. A dilated RV was not significantly correlated $(\mathrm{P}=0.095)$.

On multivariable analysis (Table 5), the model $\left(\mathrm{R}^{2}=0.591\right.$, $\mathrm{P}<0.001$ ) showed that only the indexed MVA area, RA area, and LVEDV independently predicted the TVA area with the largest contribution from the indexed MVA area $(\beta=0.420, \mathrm{P}<0.001)$.

\section{Discussion}

In this study, we present CCTA annular measurements of both the mitral and tricuspid valves in controls and examine and compare the changes that occur with PMR and SMR. There are multiple important findings. First, the MVA and TVA dimensions are significantly correlated in control subjects as wells as in patients with severe PMR and SMR. Second, the TVA enlarges in both PMR and SMR patients, even in the absence of severe TR. Third, while MVA dimensions tend to be larger in PMR patients compared to 
Table 4 Tricuspid valve annular dimensions in controls, primary, and secondary mitral regurgitation

\begin{tabular}{|c|c|c|c|c|c|c|}
\hline Variable & Controls $(\mathrm{N}=50)$ & SMR (N=25) & PMR $(\mathrm{N}=50)$ & $\begin{array}{l}\text { ANOVA P } \\
\text { value }\end{array}$ & Post hoc Tukey's test & $\begin{array}{l}\text { Tukey's test P values: } \\
\text { SMR vs. controls; PMR vs. } \\
\text { controls; PMR vs. SMR; } \\
\text { respectively }\end{array}$ \\
\hline TVA area $\left(\mathrm{cm}^{2}\right)$ & $12.64 \pm 2.25$ & $17.28 \pm 3.59$ & $14.88 \pm 3.49$ & $<0.001$ & SMR $>$ PMR $>$ controls & $<0.001 ; 0.001 ; 0.005$ \\
\hline TVA Area/BSA $\left(\mathrm{cm}^{2} / \mathrm{m}^{2}\right)$ & $6.27 \pm 1.47$ & $9.51 \pm 1.99$ & $7.76 \pm 1.77$ & $<0.001$ & SMR $>$ PMR $>$ controls & $<0.001 ;<0.001 ;<0.001$ \\
\hline TVA Peri/BSA $\left(\mathrm{mm} / \mathrm{m}^{2}\right)$ & $64.99 \pm 11.54$ & $82.89 \pm 11.25$ & $73.74 \pm 10.74$ & $<0.001$ & SMR $>$ PMR $>$ controls & $<0.001 ;<0.001 ; 0.003$ \\
\hline TVA SI distance (mm) & $45.02 \pm 5.08$ & $50.88 \pm 5.26$ & $47.86 \pm 5.49$ & $<0.001$ & SMR $>$ PMR $>$ controls $*$ & $<0.001 ; 0.022 ; 0.05^{\star}$ \\
\hline $\begin{array}{l}\text { TVA SI distance/BSA } \\
\left(\mathrm{mm} / \mathrm{m}^{2}\right)\end{array}$ & $22.38 \pm 4.46$ & $28.06 \pm 4.02$ & $25.19 \pm 4.29$ & $<0.001$ & SMR $>$ PMR $>$ controls & $<0.001 ; 0.004 ; 0.02$ \\
\hline TVA height (mm) & $7.68 \pm 2.44$ & $7.40 \pm 2.68$ & $7.32 \pm 2.56$ & 0.766 & $\mathrm{SMR}=\mathrm{PMR}=$ controls & N/A \\
\hline $\begin{array}{l}\text { TVA height/BSA (mm/ } \\
\left.\mathrm{m}^{2}\right)\end{array}$ & $3.84 \pm 1.48$ & $4.13 \pm 1.67$ & $3.88 \pm 1.45$ & 0.726 & $\mathrm{SMR}=\mathrm{PMR}=$ controls & $\mathrm{N} / \mathrm{A}$ \\
\hline TVA ratio: SI/AS & $1.27 \pm 0.24$ & $1.16 \pm 0.13$ & $1.18 \pm 0.17$ & 0.029 & $\mathrm{SMR}=\mathrm{PMR}<$ controls $^{\dagger}$ & $0.062^{\dagger} ; 0.068^{\dagger} ; 0.896$ \\
\hline
\end{tabular}

*, only a trend towards SMR larger than PMR; ${ }^{\dagger}$, only a trend towards SMR and PMR < controls. TVA, tricuspid valve annulus; SI, supero-inferior distance; AS, antero-septal distance; BSA, body surface area; PMR, primary mitral regurgitation; SMR, secondary mitral regurgitation.

SMR patients, the relative increase in TVA dimensions is greater in patients with SMR compared to PMR. Finally, the TVA annular area indexed to BSA is mainly determined by the indexed MVA area.

\section{Comparison of MVA and TVA in control subjects}

In this study, we found that among control subjects, the MVA and TVA are significantly correlated in size. However, the TVA is larger than the MVA, more eccentric (SI/AS > IC/SL), and more planar (less height). This is the largest study to examine both annuli concomitantly and the first to use CCTA as the imaging modality to do so. These findings are in concordance with a prior cardiac magnetic resonance study that assessed both annuli in 13 healthy subjects (16). Given its excellent spatial resolution, and the non-user dependent nature of the technique (compared to echocardiography), CCTA has been widely used for annular measurements and as a key tool in planning both transcatheter mitral $(26,27)$ and tricuspid interventions $(27,28)$.
Our reported MVA area indexed to BSA in controls $\left(5.1 \pm 0.86 \mathrm{~cm}^{2} / \mathrm{m}^{2}\right)$ is in concordance with prior CCTA studies reporting normal values ranging from 4.5 to $5.5 \mathrm{~cm}^{2} / \mathrm{m}^{2}$ $(5-7,29)$, with the largest study to date by Naoum and colleagues (6) indicating a mean area of $4.7 \pm 0.6 \mathrm{~cm}^{2} / \mathrm{m}^{2}$. The smaller area in their report is most likely explained by their truncation of the anterior horn of the MVA and adoption of the D-shaped rather than saddle-shaped annulus. Similarly, our TVA dimensions are in close concordance with the diastolic measurements from a recent CCTA TVA study (30). These measurements were slightly larger than diastolic echocardiographic measurements (10-14). This is most likely due to the difference in imaging modalities, as shown by Addetia and colleagues (11), who found that CT derived TVA areas to be $3.8 \pm 1.7 \mathrm{~cm}^{2}$ larger than that obtained by $3 \mathrm{D}$ echocardiography.

\section{MVA and TVA changes in both PMR and SMR}

Both PMR and SMR lead to significant MVA changes, with a larger and more circular (more relative increase 

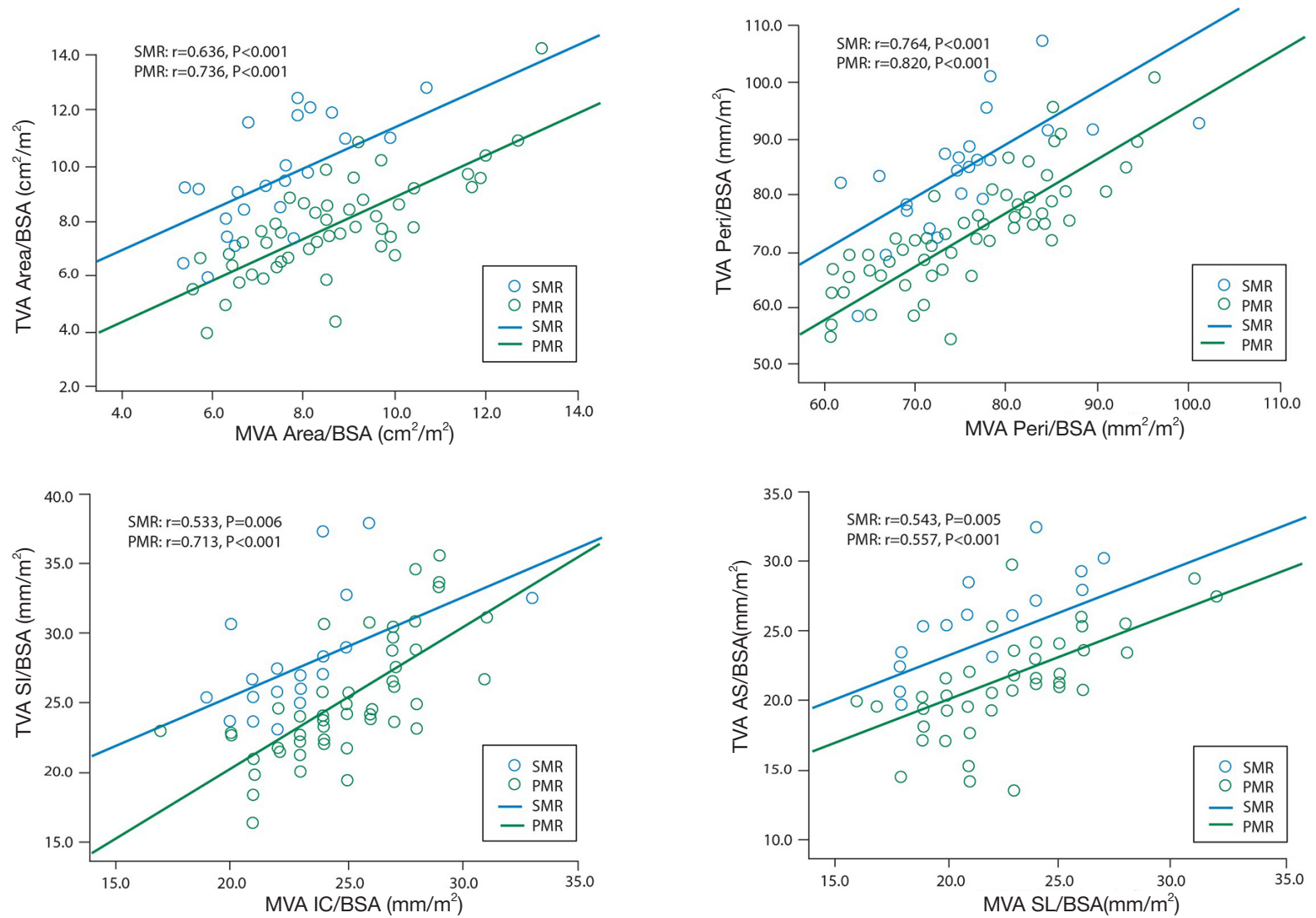

Figure 4 Correlations between mitral and tricuspid valves annular dimensions in primary and secondary mitral regurgitation. Correlations between MVA and TVA areas and perimeters, IC and SI distances, and SL and AS distances in PMR and SMR. All dimensions are indexed to BSA. MVA, mitral valve annulus; TVA, tricuspid valve annulus; BSA, body surface area; IC, intercommissural distance; SL, septo-lateral distance; AS, antero-septal distance; SI, supero-inferior distance; PMR, primary mitral regurgitation; SMR, secondary mitral regurgitation.

Table 5 Univariable and multivariable predictors of tricuspid valve annular area indexed to body surface area (TVA area/BSA)

\begin{tabular}{|c|c|c|c|c|c|}
\hline Covariate & $r$ coefficient & $P$ value (univariable) & $B(S E)$ & Beta & $\mathrm{P}$ value (multivariable) \\
\hline Female & 0.066 & 0.465 & $N / A^{*}$ & $N / A^{*}$ & $N / A^{*}$ \\
\hline Age & 0.414 & $<0.001$ & $-0.004(0.015)$ & -0.025 & 0.795 \\
\hline MVA/BSA & 0.662 & $<0.001$ & $0.420(0.084)$ & 0.430 & $<0.001$ \\
\hline $\mathrm{RA}$ area/BSA & 0.617 & $<0.001$ & $0.267(0.078)$ & 0.351 & 0.001 \\
\hline Dysfunctional RV & 0.355 & $<0.001$ & $0.108(0.619)$ & 0.017 & 0.862 \\
\hline LVEDV/BSA & 0.439 & $<0.001$ & $0.012(0.006)$ & 0.176 & 0.046 \\
\hline LVEF & -0.432 & $<0.001$ & $N / A^{T}$ & $N / A^{T}$ & $N / A^{T}$ \\
\hline RVSP & 0.345 & 0.001 & $0.007(0.12)$ & 0.050 & 0.571 \\
\hline
\end{tabular}

${ }^{*}$, not included in the multivariable model given lack of significant univariable correlation. ${ }^{ }$, not included in the multivariable model to avoid collinearity with LVEDV/BSA. BSA, body surface area; RA, right atrium; RV, right ventricle; LVEDV, left ventricular end-diastolic volume; LVEF, left ventricular ejection fraction; RVSP, right ventricular systolic pressure. 


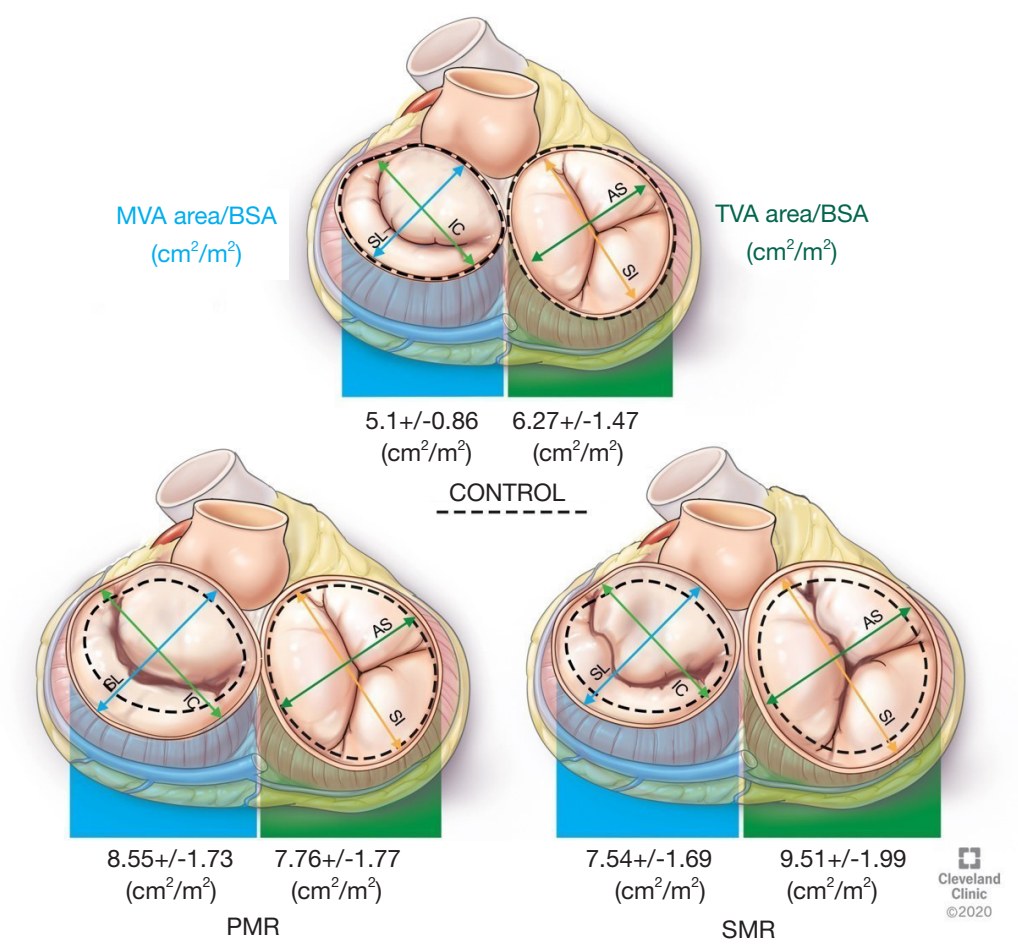

Figure 5 Summary of the MVA and TVA geometric changes in patients with PMR and SMR without significant associated TR, becoming larger and more circular. While MVA changes tend to be more pronounced in PMR, TVA changes are more pronounced in SMR. SL, septolateral distance, IC, intercommissural distance; AS, anteroseptal distance; SI, super-oinferior distance; MVA, mitral valve annulus; TVA, tricuspid valve annulus; PMR, primary mitral regurgitation; SMR, secondary mitral regurgitation; TR, tricuspid regurgitation.

in SL with a resultant decrease in IC/SL ratio) annulus than in patients without MR (Figure 5). This is consistent with prior literature $(5-7,31)$, and the tendency for these changes to be more pronounced with PMR has already been reported (6). The novel finding from this study is the impact of both forms of MR on the TVA, even without significant associated TR $(\geq 3+)$. These changes remained significant even after excluding patients with $2+$ TR (Tables S1 and S2) and patients with atrial fibrillation (Tables S3 and S4). The TVA becomes larger, with a relatively more pronounced increase in the AS distance and a tendency to become more circular (decrease in SI/AS ratio). In contrast to the MVA changes, these TVA changes are significantly more pronounced in the SMR group compared to PMR.

TVA dilation has been consistently shown to be a major determinant in the development of significant functional TR (12-14,21,22), with surgical literature $(19,24)$ and valve guidelines (15) advocating for concomitant TV repair during PMR surgery based on annular dilation regardless of the degree of TR. In the study by Dreyfus and colleagues (19), nearly $50 \%$ of patients with PMR undergoing $M V$ repair had a TVA diameter greater than twice the normal $(\geq 70 \mathrm{~mm})$. Those patients who received concomitant TV repair (on the basis of annular dilation) had significantly better functional (lower NYHA class) and echocardiographic (lower TR grade) outcomes with a trend toward improved survival. As a reference, the patients in our analysis had even larger changes of the TVA in the SMR group. It is noteworthy that our CCTA TVA measurements do not precisely reflect the anteroseptal to the anteroposterior commissural distance reported by Dreyfus et al. This distance is likely to be closer to the SI distance in our study but is not exactly the same. Future studies will be needed to correlate surgical and CCTA measurements.

With accumulating experience and data, patients with SMR are increasingly referred for transcatheter therapy given the benefits it has shown with respect to functional outcomes and survival (32). As isolated tricuspid valve surgery is not commonly performed, there has been a 
growing interest in percutaneous tricuspid repair in recent years. Small series' have demonstrated the feasibility of tricuspid annuloplasty and edge-to-edge leaflet repair, and the TriValve registry showed a reduction in heart failure hospitalization and improved survival with transcatheter TV intervention (33-35). Nevertheless, there is a lack of data regarding the optimal timing of intervention for patients with TR (36) and uncertainty with respect to the factors impacting patient selection (37). Based on the surgical outcomes data available thus far, it is at least hypothesisgenerating to suggest that a similar percutaneous approach of intervention based on TVA changes rather than TR could be considered, especially among those patients already undergoing percutaneous repair of SMR.

\section{Determinants of TVA dimensions}

In both MR groups, the MVA and TVA dimensions remained strongly and significantly correlated. When assessing the determinants of the TVA area, the MVA area was an independent and robust predictor, even after controlling for other variables. This highlights the intimate relationship between both atrioventricular annuli in healthy and diseased states. Interestingly, the RA but not the RV size was also a significant predictor of TVA changes. Comparatively, in a CCTA study assessing the determinants of MVA size in patients with SMR, LA size but not LV size was the primary determinant of MVA dimensions (6).

\section{Study limitations}

The main limitation of this study is that the MVA and TVA dimensions were measured in a single diastolic phase, though prior reports found significant variations throughout the cardiac cycle $(2,14,16)$. However, careful attention was made that all selected scans were within a similar diastolic phase. Another limitation is that contrast opacification was aimed at the left side. While this resulted in suboptimal opacification of the right heart, it did not affect the identification of the TVA borders and its segmentation. Finally, the RV size and function assessment by echocardiogram were qualitative, as a quantitative assessment is not routinely performed.

\section{Conclusions}

The normal TVA is larger, more eccentric, and more planar compared to the normal MVA in diastole. Both annuli dimensions are significantly correlated in healthy subjects and remain so in severe MR. Even in the absence of severe TR, both PMR and SMR lead to significant TVA changes, in addition to their impact on the MVA. While PMR tends to have a bigger effect on the MVA, SMR leads to more substantial changes in the TVA. These findings highlight the need for careful follow-up and consideration for early intervention on the TV in both MR groups as intervening on the dilated TVA, irrespective of the degree of TR, has been shown to be beneficial.

\section{Acknowledgments}

Funding: None.

\section{Footnote}

Reporting Checklist: The authors have completed the STROBE reporting checklist. Available at: http://dx.doi. org/10.21037/cdt-20-903

Data Sharing Statement: Available at: http://dx.doi. org/10.21037/cdt-20-903

Peer Review File: Available at: http://dx.doi.org/10.21037/ cdt-20-903

Conflicts of Interest: All authors have completed the ICMJE uniform disclosure form(available at: http:// dx.doi.org/10.21037/cdt-20-903). Dr. PW reports being a consultant at Medtronic, Cryolife and Edwards LifeSciences, outside the submitted work. PS, MD serves as an Editor-in-Chief of Cardiovascular Diagnosis and Therapy. The other authors have no conflicts of interest to declare.

Ethical Statement: The authors are accountable for all aspects of the work in ensuring that questions related to the accuracy or integrity of any part of the work are appropriately investigated and resolved. The study was conducted in accordance with the Declaration of Helsinki (as revised in 2013). The study was approved by the Institutional Review Board of the Cleveland Clinic Foundation (No. 19-811) with a waiver for informed consent.

Open Access Statement: This is an Open Access article distributed in accordance with the Creative Commons Attribution-NonCommercial-NoDerivs 4.0 International 
License (CC BY-NC-ND 4.0), which permits the noncommercial replication and distribution of the article with the strict proviso that no changes or edits are made and the original work is properly cited (including links to both the formal publication through the relevant DOI and the license). See: https://creativecommons.org/licenses/by-nc-nd/4.0/.

\section{References}

1. Levine RA, Triulzi MO, Harrigan P, et al. The relationship of mitral annular shape to the diagnosis of mitral valve prolapse. Circulation 1987;75:756-67.

2. Mihăilă S, Muraru D, Piasentini E, et al. Quantitative Analysis of Mitral Annular Geometry and Function in Healthy Volunteers Using Transthoracic ThreeDimensional Echocardiography. J Am Soc Echocardiogr 2014;27:846-57.

3. Sonne C, Sugeng L, Watanabe N, et al. Age and body surface area dependency of mitral valve and papillary apparatus parameters: assessment by real-time threedimensional echocardiography. Eur J Echocardiogr 2009;10:287-94.

4. Flachskampf FA, Chandra S, Gaddipatti A, et al. Analysis of Shape and Motion of the Mitral Annulus in Subjects With and Without Cardiomyopathy by Echocardiographic 3-Dimensional Reconstruction. J Am Soc Echocardiogr 2000;13:277-87.

5. Delgado V, Tops LF, Schuijf JD, et al. Assessment of Mitral Valve Anatomy and Geometry With Multislice Computed Tomography. JACC Cardiovasc Imaging 2009;2:556-65.

6. Naoum C, Leipsic J, Cheung A, et al. Mitral Annular Dimensions and Geometry in Patients With Functional Mitral Regurgitation and Mitral Valve Prolapse. JACC Cardiovasc Imaging 2016;9:269-80.

7. Beaudoin J, Thai WE, Wai B, et al. Assessment of Mitral Valve Adaptation With Gated Cardiac Computed Tomography: Validation With Three-Dimensional Echocardiography and Mechanistic Insight to Functional Mitral Regurgitation. Circ Cardiovasc Imaging 2013;6:784-9.

8. Rizvi A, Marcus RP, Guo Y, et al. Dynamic computed tomographic assessment of the mitral annulus in patients with and without mitral prolapse. J Cardiovasc Comput Tomogr 2020;14:502-9.

9. Badano LP, Agricola E, de Isla LP, et al. Evaluation of the tricuspid valve morphology and function by transthoracic real-time three-dimensional echocardiography. Eur J Echocardiogr 2009;10:477-84.
10. Anwar AM, Geleijnse ML, Soliman OI, et al. Assessment of normal tricuspid valve anatomy in adults by real-time three-dimensional echocardiography. Int J Cardiovasc Imaging 2007;23:717-24.

11. Addetia K, Muraru D, Veronesi F, et al. 3-Dimensional Echocardiographic Analysis of the Tricuspid Annulus Provides New Insights Into Tricuspid Valve Geometry and Dynamics. JACC Cardiovasc Imaging 2019;12:401-12.

12. Tei C, Pilgrim JP, Shah PM, et al. The tricuspid valve annulus: study of size and motion in normal subjects and in patients with tricuspid regurgitation. Circulation 1982;66:665-71.

13. Ring L, Rana BS, Kydd A, et al. Dynamics of the tricuspid valve annulus in normal and dilated right hearts: a threedimensional transoesophageal echocardiography study. Eur Heart J Cardiovasc Imaging 2012;13:756-62.

14. Fukuda S, Saracino G, Matsumura Y, et al. ThreeDimensional Geometry of the Tricuspid Annulus in Healthy Subjects and in Patients With Functional Tricuspid Regurgitation: A Real-Time, 3-Dimensional Echocardiographic Study. Circulation 2006;114:I492-8.

15. Nishimura RA, Otto CM, Bonow RO, et al. 2014 AHA/ACC Guideline for the Management of Patients With Valvular Heart Disease. J Am Coll Cardiol 2014;63:e57-185.

16. Maffessanti F, Gripari P, Pontone G, et al. Threedimensional dynamic assessment of tricuspid and mitral annuli using cardiovascular magnetic resonance. Eur Heart J Cardiovasc Imaging 2013;14:986-95.

17. Makaryus AN, Ismail H, Makaryus JN, et al. Geometric comparison of the mitral and tricuspid valve annulus: Insights from three dimensional transesophageal echocardiography. World J Cardiol 2017;9:757-60.

18. Kwan J, Kim G, Jeon M, et al. 3D geometry of a normal tricuspid annulus during systole: A comparison study with the mitral annulus using real-time 3D echocardiography. Eur J Echocardiogr 2007;8:375-83.

19. Dreyfus GD, Corbi PJ, Chan KMJ, et al. Secondary Tricuspid Regurgitation or Dilatation: Which Should Be the Criteria for Surgical Repair? Ann Thorac Surg 2005;79:127-32.

20. Dreyfus GD, Martin RP, Chan KMJ, et al. Functional Tricuspid Regurgitation. J Am Coll Cardiol 2015;65:2331-6.

21. Sagie A, Schwammenthal E, Padial LR, et al. Determinants of functional tricuspid regurgitation in incomplete tricuspid valve closure: Doppler color flow study of 109 patients. J Am Coll Cardiol 1994;24:446-53.

22. Park YH, Song JM, Lee EY, et al. Geometric and 
hemodynamic determinants of functional tricuspid regurgitation: A real-time three-dimensional echocardiography study. Int J Cardiol 2008;124:160-5.

23. Min SY, Song JM, Kim JH, et al. Geometric changes after tricuspid annuloplasty and predictors of residual tricuspid regurgitation: a real-time three-dimensional echocardiography study. Eur Heart J 2010;31:2871-80.

24. Benedetto U, Melina G, Angeloni E, et al. Prophylactic tricuspid annuloplasty in patients with dilated tricuspid annulus undergoing mitral valve surgery. J Thorac Cardiovasc Surg 2012;143:632-8.

25. Blanke P, Dvir D, Cheung A, et al. Mitral Annular Evaluation With CT in the Context of Transcatheter Mitral Valve Replacement. JACC Cardiovasc Imaging 2015;8:612-5.

26. Weir-McCall JR, Blanke P, Naoum C, et al. Mitral Valve Imaging with CT: Relationship with Transcatheter Mitral Valve Interventions. Radiology 2018;288:638-55.

27. Naoum C, Blanke P, Cavalcante JL, et al. Cardiac Computed Tomography and Magnetic Resonance Imaging in the Evaluation of Mitral and Tricuspid Valve Disease: Implications for Transcatheter Interventions. Circ Cardiovasc Imaging 2017;10:e005331.

28. Khalique OK, Cavalcante JL, Shah D, et al. Multimodality Imaging of the Tricuspid Valve and Right Heart Anatomy. JACC Cardiovasc Imaging 2019;12:516-31.

29. Gordic S, Nguyen-Kim TDL, Manka R, et al. Sizing the mitral annulus in healthy subjects and patients with mitral regurgitation: 2D versus 3D measurements from cardiac CT. Int J Cardiovasc Imaging 2014;30:389-98.

Cite this article as: Kapadia S, Krishnaswamy A, Layoun H, Griffin BP, Wierup P, Schoenhagen P, Harb SC. Tricuspid annular dimensions in patients with severe mitral regurgitation without severe tricuspid regurgitation. Cardiovasc Diagn Ther 2021;11(1):68-80. doi: 10.21037/cdt-20-903
30. Pappalardo OA, Votta E, Selmi M, et al. 4D MDCT in the assessment of the tricuspid valve and its spatial relationship with the right coronary artery: A customized tool based on computed tomography for the planning of percutaneous procedures. J Cardiovasc Comput Tomogr 2020;14:520-3.

31. Grewal J, Suri R, Mankad S, et al. Mitral Annular Dynamics in Myxomatous Valve Disease: New Insights With Real-Time 3-Dimensional Echocardiography. Circulation 2010;121:1423-31.

32. Stone GW, Lindenfeld J, Abraham WT, et al. Transcatheter Mitral-Valve Repair in Patients with Heart Failure. N Engl J Med 2018;379:2307-18.

33. Hahn RT, Meduri CU, Davidson CJ, et al. Early Feasibility Study of a Transcatheter Tricuspid Valve Annuloplasty. J Am Coll Cardiol 2017;69:1795-806.

34. Nickenig G, Weber M, Lurz P, et al. Transcatheter edgeto-edge repair for reduction of tricuspid regurgitation: 6-month outcomes of the TRILUMINATE single-arm study. Lancet 2019;394:2002-11.

35. Taramasso M, Benfari G, van der Bijl P, et al. Transcatheter Versus Medical Treatment of Patients With Symptomatic Severe Tricuspid Regurgitation. J Am Coll Cardiol 2019;74:2998-3008.

36. Baumgartner H, Falk V, Bax JJ, et al. 2017 ESC/EACTS Guidelines for the management of valvular heart disease. Eur Heart J 2017;38:2739-91.

37. Harb SC, Kapadia SR. Patients' selection for transcatheter tricuspid valve interventions: Who will benefit? Prog Cardiovasc Dis 2019;62:467-72. 


\section{Supplementary}

Table S1 Mitral valve annular dimensions in controls, primary, and secondary mitral regurgitation after excluding patients with significant TR $(>2+\mathrm{TR})$

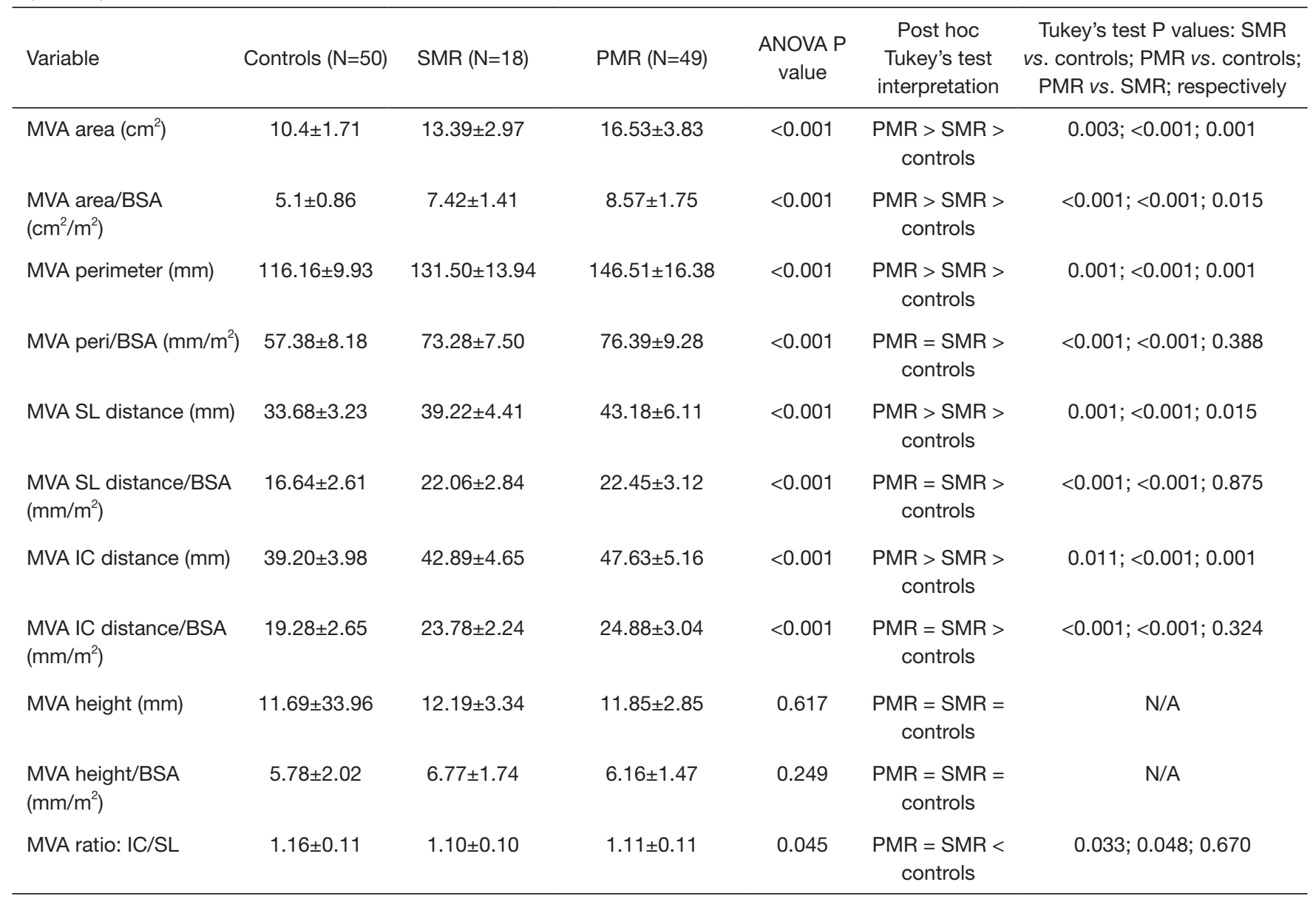

MVA, mitral valve annulus; IC, intercommissural distance; SL, septo-lateral distance; BSA, body surface area; PMR, primary mitral regurgitation; SMR, secondary mitral regurgitation. 
Table S2 Tricuspid valve annular dimensions in controls, primary, and secondary mitral regurgitation after excluding patients with significant TR $(>2+\mathrm{TR})$

\begin{tabular}{|c|c|c|c|c|c|c|}
\hline Variable & Controls $(\mathrm{N}=50)$ & $\operatorname{SMR}(N=18)$ & $\operatorname{PMR}(\mathrm{N}=49)$ & $\begin{array}{l}\text { ANOVA P } \\
\text { value }\end{array}$ & Post hoc Tukey's test & $\begin{array}{l}\text { Tukey's test P values: SMR } \\
\text { vs. controls; PMR vs. controls; } \\
\text { PMR vs. SMR; respectively }\end{array}$ \\
\hline $\begin{array}{l}\text { TVA Area/BSA } \\
\left(\mathrm{cm}^{2} / \mathrm{m}^{2}\right)\end{array}$ & $6.27 \pm 1.47$ & $9.58 \pm 2.12$ & $7.74 \pm 1.79$ & $<0.001$ & SMR $>$ PMR > controls & $<0.001 ;<0.001 ;<0.001$ \\
\hline $\begin{array}{l}\text { TVA Peri/BSA } \\
\left(\mathrm{mm} / \mathrm{m}^{2}\right)\end{array}$ & $64.99 \pm 11.54$ & $83.66 \pm 12.25$ & $73.41 \pm 10.60$ & $<0.001$ & SMR $>$ PMR > controls & $<0.001 ;<0.001 ; 0.003$ \\
\hline TVA SI distance (mm) & $45.02 \pm 5.08$ & $50.17 \pm 5.51$ & $47.82 \pm 5.54$ & 0.004 & SMR $>$ PMR > controls* & $<0.001 ; 0.022 ; 0.05^{\star}$ \\
\hline $\begin{array}{l}\text { TVA SI distance/BSA } \\
\left(\mathrm{mm} / \mathrm{m}^{2}\right)\end{array}$ & $22.38 \pm 4.46$ & $28.12 \pm 4.46$ & $25.08 \pm 4.26$ & 0.003 & SMR $>$ PMR $>$ controls & $<0.001 ; 0.004 ; 0.02$ \\
\hline TVA height (mm) & $7.68 \pm 2.44$ & $6.89 \pm 2.76$ & $7.26 \pm 2.56$ & 0.133 & $\mathrm{SMR}=\mathrm{PMR}=$ controls & $\mathrm{N} / \mathrm{A}$ \\
\hline $\begin{array}{l}\text { TVA height/BSA } \\
\left(\mathrm{mm} / \mathrm{m}^{2}\right)\end{array}$ & $3.84 \pm 1.48$ & $3.92 \pm 1.80$ & $3.83 \pm 1.43$ & 0.360 & $\mathrm{SMR}=\mathrm{PMR}=$ controls & $\mathrm{N} / \mathrm{A}$ \\
\hline TVA ratio: SI/AS & $1.27 \pm 0.24$ & $1.16 \pm 0.13$ & $1.19 \pm 0.17$ & 0.039 & $\mathrm{SMR}=\mathrm{PMR}<$ controls $^{\dagger}$ & $0.071^{\dagger} ; 0.069^{\dagger} ; 0.902$ \\
\hline
\end{tabular}

*, only a trend towards SMR larger than PMR; ${ }^{\dagger}$, only a trend towards SMR and PMR < controls TVA, tricuspid valve annulus; SI, superoinferior distance; AS, antero-septal distance; BSA, body surface area; PMR, primary mitral regurgitation; SMR, secondary mitral regurgitation. 
Table S3 Mitral valve annular dimensions in controls, primary, and secondary mitral regurgitation after excluding patients with atrial fibrillation

\begin{tabular}{|c|c|c|c|c|c|c|}
\hline Variable & $\begin{array}{l}\text { Controls } \\
(\mathrm{N}=50)\end{array}$ & $\operatorname{SMR}(\mathrm{N}=12)$ & PMR (N=39) & ANOVA P value & $\begin{array}{l}\text { Post hoc Tukey's } \\
\text { test interpretation }\end{array}$ & $\begin{array}{l}\text { Tukey's test P values: SMR } \\
\text { vs. controls; PMR vs. controls; } \\
\text { PMR vs. SMR; respectively }\end{array}$ \\
\hline MVA area/BSA $\left(\mathrm{cm}^{2} / \mathrm{m}^{2}\right)$ & $5.1 \pm 0.86$ & $6.58 \pm 0.85$ & $8.63 \pm 1.72$ & $<0.001$ & $\begin{array}{l}\mathrm{PMR}>\mathrm{SMR}> \\
\text { controls }\end{array}$ & $0.001 ;<0.001 ; 0.013$ \\
\hline MVA peri/BSA $\left(\mathrm{mm} / \mathrm{m}^{2}\right)$ & $57.38 \pm 8.18$ & $69.42 \pm 5.81$ & $77.26 \pm 8.97$ & $<0.001$ & $\begin{array}{l}\mathrm{PMR}>\mathrm{SMR}> \\
\text { controls }\end{array}$ & $<0.001 ;<0.001 ; 0.014$ \\
\hline MVA SL distance (mm) & $33.68 \pm 3.23$ & $37.58 \pm 3.65$ & $43.23 \pm 5.90$ & $<0.001$ & $\begin{array}{l}\mathrm{PMR}>\mathrm{SMR}> \\
\text { Controls }\end{array}$ & $0.022 ;<0.001 ; 0.001$ \\
\hline MVA IC distance (mm) & $39.20 \pm 3.98$ & $40.67 \pm 4.08$ & $47.28 \pm 5.35$ & $<0.001$ & $\begin{array}{l}\mathrm{PMR}>\mathrm{SMR}> \\
\text { controls }\end{array}$ & $0.080 ;<0.001 ; 0.001$ \\
\hline $\begin{array}{l}\text { MVA IC distance/BSA } \\
\left(\mathrm{mm} / \mathrm{m}^{2}\right)\end{array}$ & $19.28 \pm 2.65$ & $22.58 \pm 1.98$ & $25.03 \pm 3.01$ & $<0.001$ & $\begin{array}{l}\mathrm{PMR}=\mathrm{SMR}> \\
\text { controls }\end{array}$ & $<0.001 ;<0.001 ; 0.022$ \\
\hline MVA height (mm) & $11.69 \pm 33.96$ & $11.77 \pm 3.90$ & $11.84 \pm 2.99$ & 0.981 & $\begin{array}{c}\mathrm{PMR}=\mathrm{SMR}= \\
\text { Controls }\end{array}$ & $\mathrm{N} / \mathrm{A}$ \\
\hline $\begin{array}{l}\text { MVA height/BSA } \\
\left(\mathrm{mm} / \mathrm{m}^{2}\right)\end{array}$ & $5.78 \pm 2.02$ & $6.61 \pm 2.18$ & $6.23 \pm 1.55$ & 0.300 & $\begin{array}{l}\mathrm{PMR}=\mathrm{SMR}= \\
\text { controls }\end{array}$ & $\mathrm{N} / \mathrm{A}$ \\
\hline MVA ratio: IC/SL & $1.16 \pm 0.11$ & $1.08 \pm 0.09$ & $1.11 \pm 0.11$ & 0.006 & $\begin{array}{c}\mathrm{PMR}=\mathrm{SMR}< \\
\text { controls }\end{array}$ & $0.046 ; 0.014 ; 0.870$ \\
\hline
\end{tabular}

MVA, mitral valve annulus; IC, intercommissural distance; SL, septo-lateral distance; BSA, body surface area; PMR, primary mitral regurgitation; SMR, secondary mitral regurgitation. 
Table S4 Tricuspid valve annular dimensions in controls, primary, and secondary mitral regurgitation after excluding patients with atrial fibrillation

\begin{tabular}{|c|c|c|c|c|c|c|}
\hline Variable & Controls $(\mathrm{N}=50)$ & SMR $(N=12)$ & PMR (N=39) & $\begin{array}{l}\text { ANOVA P } \\
\text { value }\end{array}$ & Post hoc Tukey's test & $\begin{array}{l}\text { Tukey's test P values: SMR } \\
\text { vs. controls; PMR vs. controls; } \\
\text { PMR vs. SMR; respectively }\end{array}$ \\
\hline $\begin{array}{l}\text { TVA area/BSA } \\
\left(\mathrm{cm}^{2} / \mathrm{m}^{2}\right)\end{array}$ & $6.27 \pm 1.47$ & $8.74 \pm 1.67$ & $7.90 \pm 1.81$ & $<0.001$ & SMR $>$ PMR > Controls & $<0.001 ;<0.001 ; 0.072^{*}$ \\
\hline $\begin{array}{l}\text { TVA peri/BSA } \\
\left(\mathrm{mm} / \mathrm{m}^{2}\right)\end{array}$ & $64.99 \pm 11.54$ & $80.00 \pm 9.89$ & $74.85 \pm 10.83$ & 0.001 & SMR $>$ PMR $>$ controls & $<0.001 ;<0.001 ; 0.042$ \\
\hline $\begin{array}{l}\text { TVA SI distance } \\
(\mathrm{mm})\end{array}$ & $45.02 \pm 5.08$ & $48.58 \pm 5.01$ & $48.03 \pm 5.31$ & 0.011 & SMR $>$ PMR $>$ controls ${ }^{*}$ & $<0.001 ; 0.021 ; 0.05^{\star}$ \\
\hline $\begin{array}{l}\text { TVA AS distance/ } \\
\text { BSA }\left(\mathrm{mm} / \mathrm{m}^{2}\right)\end{array}$ & $17.94 \pm 3.71$ & $23.33 \pm 3.38$ & $21.73 \pm 3.61$ & $<0.001$ & SMR $>$ PMR $>$ controls & $<0.001 ;<0.001 ; 0.272^{*}$ \\
\hline TVA height (mm) & $7.68 \pm 2.44$ & $6.92 \pm 2.11$ & $7.51 \pm 2.56$ & 0.628 & SMR $=$ PMR $=$ controls & N/A \\
\hline $\begin{array}{l}\text { TVA height/BSA } \\
\left(\mathrm{mm} / \mathrm{m}^{2}\right)\end{array}$ & $3.84 \pm 1.48$ & $3.88 \pm 1.17$ & $4.04 \pm 1.51$ & 0.816 & SMR $=$ PMR $=$ controls & N/A \\
\hline TVA ratio: SI/AS & $1.27 \pm 0.24$ & $1.18 \pm 0.14$ & $1.19 \pm 0.18$ & 0.022 & $\mathrm{SMR}=\mathrm{PMR}<$ controls $^{\dagger}$ & $0.067^{\dagger} ; 0.069^{\dagger} ; 0.989$ \\
\hline
\end{tabular}

*, only a trend towards SMR larger than PMR; ${ }^{\dagger}$, only a trend towards SMR and PMR < controls TVA, tricuspid valve annulus; SI, superoinferior distance; AS, antero-septal distance; BSA, body surface area; PMR, primary mitral regurgitation; SMR, secondary mitral regurgitation. 